\title{
Long-Term Impact of Parental Divorce on Optimism and Trust: Changes in General Assumptions or Narrow Beliefs?
}

\author{
Kathryn M. Franklin, Ronnie Janoff-Bulman, and John E. Roberts \\ University of Massachusetts at Amherst
}

\begin{abstract}
Two studies were conducted to examine the long-term impact of parental divorce on beliefs about the self and others. In Study 1 , college-aged children of divorce and students from intact families did not differ on 8 basic assumptions or on measures of depression. Those whose parents had divorced, however, were less optimistic about the success of their own future marriages. Assumptions about the benevolence of people best predicted the marital optimism of the parental divorce group, but not of the intact family group. In Study 2, assumptions about the benevolence of people were explored in terms of trust beliefs. College-aged children of divorce and a matched sample from intact homes differed only on marriage-related beliefs, not on generalized trust. Children of divorce reported less trust of a future spouse and were less optimistic about marriage. Exploratory analyses found that continuous conflict in family of origin adversely affected all levels of trust.
\end{abstract}

Over the past several decades, a rising number of American marriages have ended in divorce, and, correspondingly, an increasing number of children have experienced their parents' breakup. During the 1960's and 1970's the rate of divorce sharply increased, until approximately $40 \%$ of all new marriages (Norton \& Glick, 1979) and $49 \%$ of first marriages of 25 to 34 year olds were predicted to end in divorce (Glick, 1984). Each year more than 1.1 million children are affected by parental divorce (Glick, 1979), because approximately $60 \%$ of all divorces occur within families whose members include at least one child under the age of 18 (Bane, 1979). Close to one third of all children born today are likely to experience the disruption of their parents' marriage through divorce (Glick, 1979).

Divorce is generally a stressful and extreme experience in the lives of children. Rather than a single, discrete event, parental divorce is a difficult process that can go on for years, beginning well before the actual divorce proceedings. The postdivorce family goes through a period of disorganization and must establish new patterns of interaction, both within and outside the family (Hetherington, Cox, \& Cox, 1979). Children often have to deal with challenging tasks, including implicit or even explicit loyalty demands and revisions of their beliefs about the permanence of relationships (Hess \& Camara, 1979).

Clinically oriented research has found that children of divorce experience an enormous sense of loss and often show mild depressive symptoms (Wallerstein \& Kelly, 1980). Studies have found that children of divorce are more likely to engage in delinquent and antisocial behaviors (McDermott, 1970) and to have nearly twice the rate of outpatient psychiatric evaluation as would be expected from their representation in the general population (Kalter, 1977). In many cases, the basic needs of children (i.e, physiological needs, security needs, love and belong-

Correspondence concerning this article should be addressed to Ronnie Janoff-Bulman, Department of Psychology, University of Massachusetts, Amherst, Massachusetts 01003. ing needs, and self-esteem needs) are threatened by the loss of a parent and by living in the postdivorce family (Parish \& Taylor, 1979). Nevertheless, researchers have found that divorce may actually benefit some children. Wallerstein and Kelly (1975) found a bimodal response to divorce among adolescents; some were highly accelerated academically and socially, whereas others received unaccustomed failing grades and were angry and depressed. The acceleration of some adolescents may have been due to greater responsibility and independence given to them postdivorce (Weiss, 1979) and their ability to deal with their experience constructively.

Although research has generally found that parental divorce has adverse effects on children, very few studies have examined the long-term impact of divorce. Given the expected family disorganization immediately following divorce, one would expect the greatest psychological disruption in children during this period. In fact, some research suggests that the effects of parental divorce peak at one year following the divorce, and then lessen in intensity, especially for girls (Hetherington et al., 1979). What, if any, are the longer term effects of parental divorce?

Young and Parish (1977) studied college women whose parents had been divorced during their childhood or adolescence. These women had lower self-concepts and reported a greater sense of insecurity than did college women from intact families. A cross sectional study using national probability samples from 1957 and 1976 found longer lasting, although modest, effects (Kulka \& Weingarten, 1979). Young adults (21-34 years old) who had experienced their parents' divorce before they were 16 were more likely to have gotten divorced themselves or to have never married. They were significantly less likely to report feeling "very happy" and were more likely to report that they felt an impending nervous breakdown some time during their lives and that "bad things" happen to them. Women from divorced homes valued their marital roles less than did women from intact families, and men from divorced homes valued their parental roles less (Kulka \& Weingarten, 1979). These 
researchers also found that, in general, men showed more widespread consequences than did women, supporting previous research on gender differences in children of divorce (e.g. Felner, Stolberg, \& Cowen, 1975; Hetherington et al, 1979; Peterson \& Zill, 1983; Santrock \& Warshak, 1979; cf. Slater, Stewart, \& Linn, 1983). Furthermore, the 1953 sample was more negatively affected by divorce than was the 1976 sample (Kulka \& Weingarten, 1979).

Glenn (1985) pooled eight national surveys from 1973 to 1982 and found that men and women from divorced families, when compared to respondents from intact families, scored significantly lower on several measures of psychological well-being and were more likely to be divorced themselves. Regarding the course of their intimate relationships, Greenberg and Nay (1982) found no differences in the quantity or quality of dating behavior, attitudes toward marriage, or conflict resolution skills between respondents from intact and divorced homes. The only difference found was that children whose parents had divorced expressed a more favorable attitude toward divorce in general. In contrast, Booth, Brinkerhoff, \& White (1984) reported heightened "courtship activity" among children from divorced homes.

The research on the long-term effect of parental divorce suggests that divorce may continue to have an impact on children years later. One way to begin to understand this long-term impact would be to attempt to understand the effects of divorce within a framework used to study other stressful major life events. One such perspective involves the impact of these events on individuals' basic assumptions about the world. Recent work on the reactions of victims to traumatic events suggests that these individuals' basic assumptions about the world and themselves are frequently challenged or shattered by their negative experience, and these changes in assumptions may persist years after the traumatic event (Janoff-Bulman \& Frieze, 1983; Janoff-Bulman, 1985, 1989). According to this perspective, we generally operate on the basis of certain assumptions that go unquestioned and unchallenged, and that form a fundamental core of our conceptual systems (Epstein, 1973, 1980; Horowitz, 1980, 1982; Janoff-Bulman, 1985, 1989; Parkes, 1971, 1975). Such assumptions are often related to perceptions of vulnerability, and include beliefs about the benevolence of the world and people, beliefs about how misfortune is "distributed" (i.e, according to principles of deservingness or justice, control, or randomness), and beliefs about the worthiness of the self (Janoff-Bulman, 1989).

Given the primacy of a parental relationship for the development of ideas about other people, we expected that assumptions about the benevolence of people, in particular, would be more negative for children of divorce than for children from intact families. Children whose parents are divorced have directly experienced the breakup of a relationship they are likely to have depended on and trusted; do they, then, have more negative views of people and the world in general? There is some evidence that immediately following a divorce, a child's beliefs about the world, particularly about the permanence of relationships, is shaken (Hess \& Camara, 1979) and that children experience a heightened sense of their own vulnerability (Wallerstein \& Kelly, 1980). Are these effects, apparent immediately postdivorce, still apparent years later?
In this study we sought to examine the long-term effects of divorce on the basic assumptions and beliefs of college-aged men and women. Do students from divorced homes hold different assumptions about the world and themselves than students from intact homes? Do their assumptions about the benevolence of other people and the world, in particular, differ? Furthermore, given that at this time in their lives (i.e, college years), dating and intimate relationships are of great importance, do the students from divorced homes differ from students from intact homes in terms of their views of interpersonal relationships and, more specifically, their optimism regarding their success in intimate relationships? These were the primary questions addressed in the present research. Study 1 was an attempt to tap the assumptions and beliefs of a large sample of students from divorced and intact families. This study was largely exploratory, an attempt to locate important variables for further empirical investigation. Study 2 represented a more fine-tuned examination of these variables, particularly the respondents' views of marital optimism, the benevolence of the world and the related construct, interpersonal trust.

\section{Study 1 \\ Method}

\section{Subjects}

A total of 568 university students were recruited from psychology courses and received experimental credit for their voluntary participation. Of the total sample, 190 respondents were male and 378 were female; 110 respondents reported that their parents had been divorced, and this group constituted the study's parental divorce (PD) group. There were 458 respondents in the intact family (IF) group. Men and women were distributed approximately equally across the parental divorce and intact family groups.

\section{Procedure and Questionnaire}

Respondents were told that this study was part of a research project designed to examine how certain psychosocial events affect people's beliefs about the world, although they were not specifically informed that parental divorce was the event of interest. This became clear as students completed the questionnaire, although all questions mentioning or regarding divorce were placed at the end of the questionnaire. Respondents picked up the questionnaire during class, completed it at home, and returned it during their next class meeting.

The questionnaire consisted of five sections. Section one was JanoffBulman's (1989) World Assumptions Scale (WAS). This is a 32-item scale that measures vulnerability-related beliefs about the benevolence and meaningfulness of the world and one's own self-worth (for a detailed discussion of the conceptual and psychometric development of the scale, see Janoff-Bulman, 1989). There are eight subscales that specifically tap respondents' assumptions about themselves, other people and the impersonal world: the benevolence of the world (e.g., "The world is a good place"), the benevolence of people (e.g. "People are basically kind and helpful"), justice (e.g., "Misfortune is least likely to strike worthy, decent people"), control (e.g. "Through our actions we can prevent bad things from happening to us"), randomness (e.g., "The course of our lives is largely determined by chance"), self-worth (e.g." "I am very satisfied with the kind of person I am"), personal control ("I take the actions necessary to protect myself against misfortune"), and luck ("I am basically a lucky person").

Respondents indicated their agreement or disagreement with each 
of the 32 items on 6-point scales, with endpoints 1 ("strongly disagree") and 6 ("strongly agree"). The factorial independence of the eight subscales has been supported by factor analyses, and alpha coefficients for the 4-item subscales range from .68 to .86 (Janoff-Bulman, 1989).

The second section of the questionnaire included items intended to tap beliefs about interpersonal relationships. On 8-point scales $(0=$ "not at all" and 7 = "extremely"), respondents indicated the likelihood that they would have a successful marriage, the importance of longterm intimate relationships, the acceptability of parental divorce, how positive or negative their relationship is with their mother and with their father, and how positive or negative their parents' own relationship is.

Respondents next completed the Zung Self-Rating Depression Scale (Zung, 1965). As in other past research with college students (e.g., Janoff-Bulman, 1979), a "none of the time" option was added to make the scale appropriate for a student population. In the fourth section of the questionnaire, respondents provided demographic information about gender, year in school, race, religion, and family income. They also indicated whether either parent had died and if so, how long ago, and whether their parents had been divorced.

The final section of the questionnaire was completed only by those respondents whose parents had been divorced. These subjects were asked to indicate their age at time of divorce, their custodial parent, whether their custodial parent had remarried, whether they had moved after the divorce, placement of siblings postdivorce, contact with their noncustodial parent, and parental conflict pre- and postdivorce.

\section{Results}

\section{Sample}

The PD and IF groups did not differ in terms of gender composition, year in school, race, religion, and whether their parents were still alive. The only demographic variable that differed between the groups was family income, with the IF group reporting a higher family income than the PD group (3.21 vs. $2.63, \chi^{2}=28.69, p<.0001$; on the scale, $2=\$ 10,001-$ $\$ 20,000,3=\$ 20,001-\$ 30,000$, and $4=\$ 30,001-\$ 50,000$ ).

Within the PD group, child custody was held by the mother in $87.2 \%$ of the cases, by the father in $10.1 \%$, and by someone other than a parent in $2.8 \%$. The divorce took place when the subject was of preschool age (0-4 years old) in $19.1 \%$ of the cases, elementary school age (5-10 years old) in $32.7 \%$, junior high school age (11-14 years old) in $30.9 \%$, high school age (15-18 years old) in $12.8 \%$, and over 19 years of age in $4.5 \%$ of the cases. Regarding the most recent divorces, one parental divorce had occurred within the past year and three additional divorces had occurred within the past two years. Statistical analyses indicated no significant effects due to age on any of the dependent measures; this was the case whether age was analyzed correlationally (i.e., using actual age of child at the time of divorce) or with analyses of variance (ANOVAs; i.e, using schoolaged groupings). The custodial parent had remarried in $39.3 \%$ of the cases.

\section{Group Comparisons}

A $2 \times 2$ (Gender $\times$ Marital Status) multivariate analysis (MANOVA) on the eight subscales of the WAS (Janoff-Bulman, 1989) did not indicate a significant main effect for marital sta- tus, $F(8,538)=1.68, n s$, indicating no differences between the PD and IF groups on general assumptions about themselves and the world. Univariate ANOVAs $(2 \times 2$, Gender $\times$ Marital Status) were conducted to more closely examine possible differences between the PD and IF respondents. Again, significant differences were not found, not even for the benevolence of people and benevolence of world assumptions, $F(1,545)=1.01$, $n s$, and $F(1,545)=0.48, n s$, respectively; $F$ values for the other six subscales ranged from 0.58 to $1.99(p<.16)$. Furthermore, a $2 \times 2$ (Gender $\times$ Marital Status) ANOVA found no group differences on the Zung Self-Rating Depression Scale (Zung, 1965). The PD and IF groups, then, did not appear to differ in terms of their basic assumptions nor in levels of depression as measured in the present study.

There were no significant Gender $\times$ Marital Status interactions found for any of the assumptions or for the Zung Self-Rating Depression Scale (Zung, 1965). A main effect for gender, $F(8,538)=4.19, p<.001$, emerged in the $2 \times 2$ (Gender $\times$ Marital Status) MANOVA for the eight subscales of the WAS. Univariate ANOVAS on the assumptions found that women's scores were significantly different from men's scores on the three meaning subscales; women were more likely than men to believe in randomness, $F(1,554)=7.82, p<.005$, and less likely to believe in control, $F(1,554)=12.34, p<.001$, and justice, $F(1,554)=11.38, p<.001$. Furthermore, ANOVAs conducted on the questions regarding interpersonal relationships revealed that women reported that they were more likely to have successful marriages than did men $(5.99$ vs. $5.70, F(1$, $560)=6.81, p<.001)$.

Analyses revealed group differences between the PD and IF groups on several of the interpersonal items. The PD respondents thought they would be less likely to have long and successful marriages ( 5.65 vs. $5.95, F(1,554)=5.46, p<.02$ ), reported poorer relationships with their fathers $(7.90$ vs. $11.36, F(1$, $554)=80.97, p<.001$ ), and thought parental divorce was more acceptable than did those in the IF group ( 4.90 vs. $3.29, F(1$, $554)=42.67, p<.001$ )

To further explore the difference in optimism about future marriage, we conducted separate multiple regression analyses for the PD and IF groups, using expected success in marriage as the criterion variable and simultaneously entering the eight assumptions as measured by the WAS (Janoff-Bulman, 1989). For the PD group, the eight assumptions accounted for $27 \%$ of the variance in marital optimism, $F(8,538)=4.66, p<.001$. Benevolence of people accounted for the greatest proportion, $15 \%$ of the variance $(F$ to enter $=21.30, p<.001)$. Benevolent world and personal control also emerged as significant predictors, although they accounted for only $1 \%$ ( $F$ to enter $=6.67, p<.05$ ) and $2 \%$ ( $F$ to enter $=5.23, p<.05)$ of the variance, respectively. For the IF group, the eight assumptions accounted for $12 \%$ of the variance in optimism about marriage, $F(8,538)=7.06, p<$ .001 . Self-worth, and not benevolence of people, accounted for the greatest proportion, $5 \%$ of the variance ( $F$ to enter $=10.39$, $p<.001)$. Personal control and justice were also significant predictors, but accounted for only $2 \%$ ( $F$ to enter $=7.73, p<.01$ ) and $1 \%$ ( $F$ to enter $=4.25, p<.05$ ) of the variance, respectively.

The regression coefficients for these two regression analyses are presented in Table 1 . The regression coefficients for benevolence of people and self-esteem, the strongest predictors of 
Table 1

Regression Coefficients for the Prediction

of Optimism About Success in Marriage

\begin{tabular}{|c|c|c|c|c|c|}
\hline \multirow{2}{*}{$\begin{array}{c}\text { Basic } \\
\text { assumption }\end{array}$} & \multicolumn{2}{|c|}{ PD group } & \multicolumn{2}{|c|}{ IF group } & \multirow[b]{2}{*}{$p^{b}$} \\
\hline & $\beta$ & Unstand. & $\beta$ & Unstand. & \\
\hline \multirow{2}{*}{\multicolumn{6}{|c|}{$\begin{array}{l}\text { Benevolence } \\
\text { of people } \\
\text { Benevolence } \\
\text { of the }\end{array}$}} \\
\hline & & & & & \\
\hline world & $-.279^{*}$ & -.074 & -.026 & -.006 & $<.05$ \\
\hline Justice & -.045 & -.013 & .123 & .029 & $n s$ \\
\hline Control & .006 & .002 & -.096 & -.025 & $n s$ \\
\hline Randomness & -.143 & -.039 & -.080 & -.019 & $n s$ \\
\hline Self-worth & -.025 & -.006 & $.169^{*}$ & .037 & $<.05$ \\
\hline Personal & & & & & \\
\hline control & $.234^{*}$ & .061 & $.152^{*}$ & .040 & $n s$ \\
\hline Luck & .132 & .034 & .035 & .007 & $n s$ \\
\hline
\end{tabular}

Note. $\mathrm{PD}$ group $=$ parental divorce group; $n=110 . \quad$ IF group $=$ intact family group; $n=458$. $\beta=$ standardized regression coefficient; Unstand. = unstandardized regression coefficient.

"As measured by the World Assumptions Scale. ' ${ }^{\text {b }}$ This $p$ value refers to the difference between the regression coefficients for the PD and IF groups.

$* p<.05$. ** $p<.001$.

marital optimism for the PD and IF groups, respectively, were significantly different across the two groups, $t(548)=3.78, p<$ .001 and $t(548)=1.72, p<.05$; benevolence of people was more strongly associated with marital optimism for the PD group, and self-esteem was more strongly associated with marital optimism for the IF group. Regression coefficients for the benevolence of the world were also significantly different for the PD and IF groups, $t(548)=2.06, p<.05$.

It should be noted that the data in Table 1 suggest instances of suppression (see Cohen \& Cohen, 1975); in several cases the standardized regression coefficients exceed the zero-order correlations or are different in sign. This is particularly apparent for benevolence of the world, which has a zero-order correlation of .09 (ns) with marital optimism for the PD group, but a regression coefficient of -.279 . It seems that benevolence of the world operated largely as a suppressor, suppressing a portion of the variance of benevolence of people that is irrelevant to marital optimism; the zero-order correlation between benevolence of people and marital optimism for the PD group was .40 ( $p<$ .001 ), whereas the regression coefficient was .50 .

The zero-order correlation between benevolence of people and marital optimism for the IF group was .16 $(p<.001)$. The correlations between self-esteem and marital optimism were $.19(p<.05)$ for the PD group and $.27(p<.001)$ for the IF group. The correlation between self-esteem and benevolence of people was similar (approximately .25) for both the PD and IF groups. However, as shown in Table 2 , self-worth and benevolence of people were both significantly associated with parental (i.e., mother and father) relationships for IF respondents, whereas for PD respondents only benevolence of people was associated with parental relationships, specifically the relationship with one's mother and frequency of talking to and seeing one's noncustodial parent (the father in almost all cases). For those whose parents had been divorced, self-worth was unrelated to any parental relationship variables.

\section{Discussion}

In this study, college students from divorced backgrounds and those from nondivorced backgrounds did not differ in depression or on any of the eight assumptions measuring benevolence and meaningfulness of the world and self-worth. If parental divorce is associated with depression and low self-esteem in children, as other researchers have suggested (e.g., Hetherington et al., 1979; Wallerstein \& Kelly, 1980), this association is most apparent in the time period immediately following the divorce. The present study suggests that decreased self-esteem and depression may not characterize college-aged children of divorce.

Although there do not appear to be long-term differences in depression or general assumptions about themselves or their world, there seem to be long-term differences between the two groups in how these broad assumptions feed into and influence some narrower, more specific beliefs about interpersonal relationships. Results indicated that the life event of parental divorce is related to college-aged students' beliefs that they will have less successful future marriages. This finding supports recent work by Wallerstein (1987; Wallerstein \& Blakeslee, 1989), who found that 16-18-year-old children of divorce, particularly young women, repeatedly mention a sense of vulnerability and a fear of being hurt in romantic relationships. Despite the intention to marry and the belief in romantic love, twothirds of Wallerstein's (1987; Wallerstein \& Blakeslee, 1989) respondents were apprehensive about the possible breakup of their own future marriages.

In the present study, it was particularly interesting that for those whose parents had been divorced, the assumption about the benevolence of people was the strongest predictor of one's own marital optimism, whereas for those whose parents had not been divorced, the assumption of self-worth was the strongest predictor. The two groups did not differ overall in terms of their assumptions. The parental divorce group did not view people more negatively nor trust them less, yet they implicitly recognized the role of other people in determining the outcome of a marriage. Their responses seemed to reflect a more conjoint, interdependent vision of marital relationships.

In contrast, respondents whose parents had not been divorced did not appear to focus on the role of others. The greater marital optimism of the IF group may reflect positive illusions, and their focus on themselves and their own self-worth when assessing the likelihood of marital success is consistent with such an analysis (see Taylor \& Brown, 1988). If they believed they were good and worthy, they felt that their marriages would be successful, more or less regardless of their partner's attributes. For those whose parents had been divorced, however, if they believed other people are good and trustworthy, they felt their marriages would be successful, more or less regardless of their own perceived self-worth. Through parental divorce, these students were made more aware of the role of one's partner in determining the outcome of a relationship.

For those whose parents had not divorced, negative relationships with either parent were associated not only with more negative views of people, but also with more negative views of 
Table 2

Correlations of Benevolence of People and Self-Worth Assumptions with Parental Relationship Variables

\begin{tabular}{ccccccccc}
\hline & \multicolumn{3}{c}{ PD group } & & \multicolumn{3}{c}{ IF group } \\
\cline { 2 - 4 } $\begin{array}{c}\text { Parental } \\
\text { relationship }\end{array}$ & $\begin{array}{c}\text { Benevolence } \\
\text { of people }\end{array}$ & $\begin{array}{c}\text { Self- } \\
\text { worth }\end{array}$ & $\begin{array}{c}\text { Marital } \\
\text { optimism }\end{array}$ & $\begin{array}{c}\text { Benevolence } \\
\text { of people }\end{array}$ & $\begin{array}{c}\text { Self- } \\
\text { worth }\end{array}$ & $\begin{array}{c}\text { Marital } \\
\text { optimism }\end{array}$ \\
\hline $\begin{array}{c}\text { Relationship with } \\
\text { mother }\end{array}$ & $.35^{* * *}$ & .06 & $.25^{*}$ & & $.20^{* * *}$ & $.32^{* * *}$ & $.30^{* * * *}$ \\
$\begin{array}{c}\text { Relationship with } \\
\text { father }\end{array}$ & .07 & .07 & .11 & & $.19^{* * *}$ & $.29^{* * * *}$ & $.25^{* * * *}$ \\
$\begin{array}{c}\text { Talk with noncustodial } \\
\text { parent postdivorce }\end{array}$ & $.28^{* *}$ & .05 & .18 & & & & \\
$\begin{array}{c}\text { See noncustodial } \\
\text { parent postdivorce }\end{array}$ & $.20^{*}$ & .02 & .11 & & & & \\
\hline
\end{tabular}

Note. PD group = parental divorce group; $n=110$. IF group = intact family group; $n=458$.

${ }^{*} p<.05$. $^{* *} p<.01$. $^{* * *} p<.001$.

themselves. For those whose parents had divorced, the more negative the relationship with one's mother and the less contact with one's father (in most cases), the more negative one's view of other people. Yet these variables were unrelated to respondents' views of themselves and their own self-worth. It is as if respondents whose parents have been divorced have insulated their own perceptions of self-worth from parental relationships. One means of coping with divorce may involve psychologically separating oneself from one's parents and one's parents' conflicts. In this way, children of divorce can still, at least over time, feel good about themselves even if their parents have a negative relationship (see, e.g., Wallerstein \& Kelly, 1980).

Two noteworthy "nonfindings" in this study were the lack of interactions with gender and the lack of age-related differences in the parental divorce group. There were main effects for gender; women were more optimistic about marriage, and believed in a less meaningful world (i.e., assumed the world was less just, less controllable, and more random). Yet men and women did not respond differently on any of the divorce-related variables (cf. Wallerstein, 1987; Wallerstein \& Blakeslee, 1989). Although researchers have suggested that boys fare worse than girls after a divorce and tend to exhibit more lingering effects (Hetherington et al, 1979; Peterson \& Zill, 1983; Wallerstein \& Kelly, 1980), on the variables examined in this study, the long-term outcomes for men and women may not differ.

A second noteworthy "nonfinding" was that subjects' age at the time of divorce was not related to any long-term outcome measures used in the study. It should be noted that in this study the current age of respondents was approximately the same (all college-aged), and thus age at time of divorce and time since divorce were naturally confounded and could not be examined separately. Nevertheless, much past research has suggested that children's age at the time of divorce is a critical factor in children's reactions (e.g, Longfellow, 1979; Wallerstein, 1983; Wallerstein \& Kelly, 1980). This is no doubt the case in terms of immediate responses to parental divorce. However, long-term outcomes, at least in the cognitive domains explored in this research, may look very similar, regardless of the child's age at the time of divorce.
Respondents in this study were young adults, at the age when they are thought to be working through the developmental task of intimacy versus isolation (Erikson, 1968). The parental divorce they experienced during childhood or adolescence may be reactivated and somehow incorporated during this stage, regardless of when the divorce was initially experienced. Parental divorce, then, may be understood in light of age-appropriate issues regarding beliefs about one's own relationships and future marriage. In support of this perspective, the major differences found in the present study were not those involving generalized assumptions about oneself or one's world, but rather those related to expectations about one's own marriage, the acceptability of divorce, and the role played by other people in the determination of a successful marriage.

We conducted Study 2 to further investigate possible differences in assumptions and interpersonal beliefs between college-aged students whose parents had been divorced and college-aged students whose parents were still married. The study was intended to correct for methodological weaknesses in Study 1 and to focus more specifically on the question of whether differences between the groups can best be understood in terms of narrow beliefs about marriage, more general beliefs about relationships, or very generalized beliefs about people.

\section{Study 2}

Issues of intimacy in interpersonal relationships are particularly salient during late adolescence. College-aged children of divorce have experienced the disruption of fundamental relationships and thus may be more wary of others in intimate relationships. In her longitudinal study of children of divorce, Wallerstein (1987) found that one-half of her sample of young men and women (16-18 year olds) feared being betrayed, not only in future relationships, but in their present relationships as well (also see Wallerstein \& Blakeslee, 1989). Wallerstein's work, although impressive for its longitudinal focus, fails to provide comparisons with control groups of children from intact homes. Perhaps fears about betrayal and concerns about 
trust are present in many adolescents, regardless of parental background.

In Study 1, college-aged children of divorce did not view other people as less benevolent than did college-aged children from intact homes. Yet the marital optimism of those whose parents had been divorced was best accounted for by their assumptions about the benevolence of others, which was not the case for their intact-family counterparts. The benevolence of other people can be considered very broadly or quite narrowly; the extent to which one views other people, in general, as benevolent is conceivably very different from the extent to which one views a particular person (e.g., one's parent or dating partner) as benevolent. Both are essentially measures of interpersonal trust, with the former representing generalized trust in other people and the latter representing interpersonal trust of a particular individual. Recent social psychological work has suggested that interpersonal trust encompasses beliefs in the integrity of another individual (faith); beliefs that a partner is truly interested in the other's welfare; honesty and dependability (fulfillment of promises); and predictability (Larzelere \& Huston, 1980; Rempel, Holmes, \& Zanna, 1985). To a child who has witnessed the dissolution of marriage and has "lost" a parent as a result, the ability to depend on others and have faith in others within intimate relationships may be particularly problematic.

In this study we sought to examine possible differences in perceived trust between college students whose parents had been divorced and college students whose parents were still married. Two different levels of trust were explored: generalized trust (i.e, abstract beliefs about the benevolence of others) and interpersonal trust of specific others, including parents, intimates not related to marriage (i.e., best friend and dating partner), and intimates related to marriage (i.e., hypothetical marital partner).

On the basis of the results of Study 1, we did not expect generalized trust to differ between the two groups. Daily experience with other people may restore a child's faith in the benevolence of people in general. Yet the dissolution of a marriage, resulting in the loss of or estrangement from a parent, may caution a child against intimacy and may affect trust in close relationships. We expected differences in interpersonal trust, and the specific nature of these differences seemed important to explore. Do college students whose parents have been divorced trust intimate others less? In other words, do they trust best friends or dating partners less than do those who have not experienced parental divorce? Or is there decreased trust not of all intimates but only of those specifically related to marriage? At the most basic level, divorce exemplifies a failed marriage, and trust therefore might be most problematic in intimate relationships in this context. The young-adult child of divorce may be able to accept intimacy in dating relationships, but be particularly cautious about marriage; that is, a partner may be perceived as trustworthy in a dating situation, but regarded with caution as a potential spouse.

In this study, a measure of optimism about marriage was again included, but a distinction was drawn between optimism about marriage and optimism about dating. This distinction was intended to echo and correspond to differences in measures of interpersonal trust. A major weakness of Study 1 was that the questionnaire was completed at home by respondents, many of whom no doubt flipped through the pages to determine the "real purpose" of the study. The latter questions about divorce might have sensitized those whose parents had been divorced, such that they responded in a socially desirable way. In the present study, respondents completed materials in a lab without knowing the study's intent.

\section{Method}

\section{Subjects}

Respondents were 114 college-aged students; 57 were students whose parents had been divorced (parental divorce or PD group) and 57 were matched control students (intact family or IF group) whose parents were not divorced. All respondents were recruited from introductory psychology classes. Of the 57 pairs of students, 31 were male and 26 were female.

\section{Procedure}

At the beginning of the semester, the experimenter distributed a one-page demographic survey to a large sample of volunteer students in introductory psychology courses. Items included age, gender, race, religion, strength of religious faith, year in school, respondent marital status, parental education, number of siblings, size of city or town where respondent was raised, and parental marital status. Several weeks later a sub-sample of this population was contacted by phone and invited to participate in a study on people's beliefs about themselves and the world; students were unaware of the experimenters' interest in parental divorce.

Students who indicated that their parents had been divorced were most actively recruited. For each of these respondents who agreed to participate, another respondent from the sample of students whose parents were still married was chosen and was matched on the basis of age, gender, race, religion, the strength of their religious faith, and year in school. Additionally, to whatever extent possible, subjects were also matched on parental education and income, number of siblings, and size of town or city where raised. More than one IF respondent was matched, on paper, to each PD respondent to improve the chances of participation of a matched control.

Respondents completed the study questionnaire in groups of five to ten, with both PD and IF group members present at each session. The questionnaire was distributed in four separate sections, both to minimize the perceived length of the questionnaire and, more important, to insure that the term "divorce" was not seen by respondents while filling out the essential study scales. All items mentioning or related to divorce appeared only in the final section of the questionnaire, which was distributed after all previous sections had been completed.

The questionnaire was divided into sections as follows: Section 1 included scales designed to tap generalized trust (i.e., beliefs in human benevolence in general); Section 2 included the interpersonal trust scales for best friend, dating partner, and hypothetical spouse and items regarding optimism about future relationships and marriage; Section 3 included items related to the respondent's relationship with his or her biological parents while growing up and estimates of trust between the biological parents; and Section 4 contained the demographic and divorce-related items. On completion of the questionnaire, respondents were thoroughly debriefed as to the intent of the study.

\section{Questionnaire}

Generalized trust. In Section 1 of the questionnaire, respondents were asked to complete Janoff-Bulman's (1989) WAS. Although eight assumptions are measured by the scale, in the present study we focused 
mainly on respondents' assumptions about the benevolence of other people and, secondarily, their assumptions about the benevolence of the world (i.e., the impersonal world) as generalized measures of trust. Reliabilities for the eight subscales ranged from .62 to .82 . The two subscales of most interest had the highest alphas, with alpha $=.82$ for the benevolence of people and alpha $=.81$ for the benevolence of the world.

Respondents then completed the Belief in Human Benevolence Scale (BHB; Thornton \& Kline, 1982), which measures opinions about people's natural benevolence. Using the 6-point scales ("strongly agree" to "strongly disagree"), students indicated their agreement with such statements as "People are pleased if they see someone happy" and "Given the opportunity, people are dishonest." In designing this questionnaire, Thornton and Kline reported reliability coefficients for their three samples of $.77, .76$, and .78. In the present study the alpha coefficient for the scale was .87 ; the BHB was highly correlated with both the Benevolence of People subscale $(r=.74, p<.01)$ and the Benevolence of the World subscale $(r=.73, p<.01)$ of the WAS (JanoffBulman, 1989),

Interpersonal trust in the context of marriage. Rempel, Holmes \& Zanna (1985) designed a 17-item Trust Scale (TS) to measure levels of trust within close relationships. Items were tailored to represent three distinct aspects of trust: predictability, dependability, and faith. Predictability involves beliefs about the consistency of a partner's behavior (e.g. "My partner behaves in a very consistent manner"), dependability focuses on dispositional qualities of the partner that enable a person to feel confident in the face of risk and potential hurt (e.g., "I can rely on my partner to keep the promises he or she makes to me"), and faith entails one's confidence in the relationship and the responsiveness of the partner when facing an uncertain future (e.g., "Though times may change and the future is uncertain, I know my partner will always be ready and willing to offer me strength and support"). Rempel, Holmes and Zanna reported alpha reliabilities of .70, .72, and .80 for the Predictability, Dependability, and Faith subscales respectively. In the present study, reliabilities were $.55, .69$, and .81 for the predictability, dependability and faith subscales, respectively.'

In this study, we used Rempel, Holmes, \& Zanna's (1985) TS to tap subjects' beliefs about the extent to which they would trust their marital partner. Respondents were asked to imagine that they are in the first year of marriage and, as realistically as possible, to respond to statements about their spouse on 6-point scales with endpoints of 1 (strongly disagree) and 6 (strongly agree). In addition, two items were designed to tap more specific beliefs about marital optimism. Students reported their beliefs about the likelihood that they would get married and the likelihood that they would have a successful marriage. These two items were highly correlated $(r=.67)$ and were therefore summed to yield a single measure of marital optimism.

Interpersonal trust. We also assessed the impact of parental divorce on close relationships outside of the marital context. Given the intent to measure trust of a close friend, dating partner, and parents, a scale briefer than the 17-item TS (Rempel, Holmes, \& Zanna, 1985) was used. The 8-item Dyadic Trust Scale (DTS) was developed by Larzelere and Huston (1980) to measure the extent to which one trusts a partner. Examples of scale items include "I feel that I can trust my partner completely," "My partner is primarily interested in his/her own welfare," and "I feel that my partner can be counted on to help me." The authors report that the scale measures a single factor, has high reliability (alpha $=.93)$ and is uncorrelated with social desirability $(r=$ $.00, n s)$.

Subjects completed the DTS using first an intimate romantic partner and then their best friend as the reference person. Respondents who were not presently dating were instructed to refer to a hypothetical intimate romantic partner. A single item measuring the importance of long-term intimate relationships and another measuring the importance of friendship followed each scale. In this study, reliability for the scale was .90 when completed with reference to an intimate, and .88 with reference to a best friend.

Two items were also designed to measure respondents' general optimism about future relationships: How confident they were that they would have successful love relationships in the future and how optimistic they were that these relationships would be successful. These two items were highly correlated $(r=.83)$ and were therefore summed to provide a single measure of optimism about future relationships, which was to be differentiated from optimism more specifically about marriage.

The DTS was then repeated for respondents' perceptions of how they viewed their relationship with their biological mother and their biological father while growing up. These two scale scores were intended to provide some indication of the association between parental divorce and trust of parents, and had alpha coefficients in the present study of .93 and .95. Finally, respondents completed the scale measuring how they believed their biological mother viewed their biological father while the respondent was growing up and how they believed their biological father viewed their biological mother while the respondent was growing up. Sample items were: "My mother felt that my father was primarily interested in his own welfare" and "My father felt that my mother could be counted on to help him."

Demographics. The final section of the questionnaire contained the same demographic items asked of the respondents surveyed earlier in the semester (e.g., age, gender, race, religion, parents' marital status). In addition, those whose parents were still married indicated how happily married their parents were and how much conflict there was in their parents' marriage on 5-point scales with endpoints not at all and extremely. The topic of divorce was introduced in this final section of the questionnaire. The last page was completed only by those whose parents had been divorced. The PD respondents were asked to indicate how positive or negative their views of their parents were before the divorce, during the year following the divorce, and now, as well as their perceptions of the perceived impact of the divorce on them at the time of the divorce and now. Questions regarding relationship with noncustodial parent, contact with noncustodial parent, and relationship with stepparent, if relevant, were included, as were three questions asking respondents to indicate the extent of conflict in their parents' relationship before the divorce, in the few years after the divorce, and now. Responses were made on 5-point scales with endpoints not at all and extremely.

\section{Results}

Statistical analyses on the demographic variables indicated no differences between the PD respondents and their matched controls in the IF group. All subsequent analyses therefore compared differences between groups rather than pair-wise comparisons between individuals.

\footnotetext{
${ }^{1}$ Item \#6 ("I feel very uncomfortable when my partner has to make decisions which will affect me personally") was deleted from the 6item Dependability subscale of the Trust Scale (Rempel, Holmes, \& Zanna, 1985) to increase the alpha coefficient from .63 to .69 . The elimination of any other item would have decreased, rather than increased, the alpha coefficient. Analyses were rerun with the less reliable 6-item scale as well, and results were essentially unchanged. In the case of the Predictability subscale, which had a relatively low alpha coefficient (.55), there was no single item that stuck out as particularly poor, and the elimination of any item would have resulted in a 3-item scale.
} 
Table 3

Comparison of Mean Values for Trust and Optimism Scales by Parents' Marital Status ${ }^{\mathrm{a}}$

\begin{tabular}{|c|c|c|c|c|}
\hline \multirow{2}{*}{$\begin{array}{c}\text { Trust and optimism } \\
\text { variables }\end{array}$} & \multicolumn{2}{|c|}{ PD group } & \multicolumn{2}{|c|}{ IF group } \\
\hline & $M$ & $S D$ & $M$ & $S D$ \\
\hline \multicolumn{5}{|l|}{ Generalized trust } \\
\hline Benevolence of people (WAS) & 17.26 & 4.67 & 18.04 & 2.90 \\
\hline Benevolence of world (WAS) & 16.10 & 5.08 & 16.86 & 3.30 \\
\hline $\begin{array}{l}\text { Belief in human benevolence } \\
\text { (BHB) }\end{array}$ & 82.33 & 12.85 & 83.21 & 10.01 \\
\hline \multicolumn{5}{|l|}{ Interpersonal trust } \\
\hline \multicolumn{5}{|l|}{ Parents } \\
\hline Trust in mother & $36.67 * *$ & 10.85 & 41.37 & 7.60 \\
\hline Trust in father & $30.86 * * *$ & 13.67 & 39.39 & 8.33 \\
\hline Mother's trust in father & $21.10^{* * *}$ & 10.32 & 36.88 & 9.11 \\
\hline Father's trust in mother & $26.98^{* * *}$ & 10.03 & 39.30 & 8.10 \\
\hline \multicolumn{5}{|l|}{ Intimates-nonmarriage } \\
\hline Trust in best friend & 39.20 & 7.29 & 39.11 & 7.68 \\
\hline Trust in dating partner & 36.37 & 7.72 & 38.46 & 7.13 \\
\hline Optimism toward dating & & & & \\
\hline relationships & 5.51 & 1.57 & 5.88 & 1.71 \\
\hline \multicolumn{5}{|l|}{ Intimates-marriage } \\
\hline Dependability of spouse & $22.82^{*}$ & 4.62 & 24.59 & 3.64 \\
\hline Faith in spouse & 36.06 & 4.63 & 35.73 & 4.28 \\
\hline Predictability of spouse & 17.57 & 3.67 & 16.86 & 3.61 \\
\hline Optimism toward marriage & $5.65^{*}$ & 1.26 & 6.21 & 1.33 \\
\hline
\end{tabular}

Note. $\mathrm{PD}$ group $=$ parental divorce group, $n=57 ; \mathrm{IF}$ group $=$ intact family group, $n=57$; WAS = World Assumptions Scale; BHB = Belief in Human Benevolence Scale.

"Asterisks refer to differences between the means of the PD and IF groups.

${ }^{*} p<.05 .{ }^{* *} p<.01 . * * * p<.001$.

\section{Group Comparisons}

A $2 \times 2$ (Gender $\times$ Parents' Marital Status) MANOVA, using the optimism and trust measures as dependent variables, revealed a significant main effect for parents' marital status, $F(14,90)=4.45, p<.001$. Univariate ANOVAs indicated no significant differences between the PD and IF respondents on the generalized measures of trust-the BHB (Thornton \& Kline, 1982) and the benevolence of people and benevolence of the world subscales of the WAS (Janoff-Bulman, 1989). Separate analyses found no significant differences between the PD group and the IF respondents on any of the eight subscales of the WAS; $F$ values for the eight subscales ranged from 0.42 to $1.83(p<.19)$. The ANOVAs did reveal some significant differences between the PD and IF groups on measures of interpersonal trust. Specifically, significant differences emerged on measures of parent trust and spouse trust.

As shown in Table 3, and not surprisingly, respondents reported less trust between divorced mothers and fathers than between mothers and fathers in intact families, for mothers: $F(1,105)=75.34, p<.001$; for fathers: $F(1,105)=54.86, p<$ .001 . Furthermore, respondents' mean scores differed on the extent to which they reported trusting their parents while growing up, for both mother, $F(1,106)=8.60, p<.005$, and father, $F(1,106)=18.39, p<.001$, with those in the PD group trusting their parents less than did those in the IF group. Given that maternal custody characterized $77.2 \%(n=44)$ of the PD group, we anticipated a decreased level of trust in father, but not of trust in mother. To ascertain whether the diminished trust in mothers was unduly influenced by those few individuals in this study whose mothers did not retain custody, $2 \times 2$ (Gender $\times$ Parents' Marital Status) ANOVAs were run including only this maternal-custody group. All previously significant variables remained significantly different for the PD and IF groups, including decreased trust in mother.

There were no significant differences between the PD and IF groups in trust of best friend or dating partner (i.e., nonmarriage intimates) or in optimism about future relationships (see Table 3). Because not all respondents were presently involved in a dating relationship, those who did not have a dating partner were asked to imagine themselves in a serious dating relationship while completing the DTS (Larzelere \& Huston, 1980). $T$ tests indicated similar numbers of students dating in each group ( $n=27$ for the PD group and $n=33$ for the IF group), and no significant differences emerged on demographic variables between those dating and those not dating. ANOVAs ( $2 \times 2$, Gender $\times$ Parents' Marital Status) focusing only on those who were dating continued to indicate no differences with respect to trust in a dating relationship (38.26 vs. 39.15 , $F(1,56)=.10, n s)$ or optimism toward future relationships $(6.00$ vs. $6.42, F(1,56)=.82, n s)^{2}$

Although PD and IF respondents did not differ in trust and optimism regarding present and future dating relationships, they did significantly differ on measures of trust and optimism in the context of marriage. As shown in Table 3, respondents whose parents had been divorced viewed their future spouse as less dependable, $F(1,106)=4.02, p<.05$, as measured by the Dependability subscale of Rempel, Holmes, and Zannas (1985) TS, and were less optimistic about their own future marriage, $F(1,106)=5.14, p<.05$, than their IF counterparts. Although in this case all respondents were asked to imagine themselves married, $2 \times 2$ (Gender $\times$ Parents' Marital Status) ANOVAs were also run on only those who were presently dating. Results revealed that the main effect of parents' marital status on how optimistically respondents viewed their own future marriage remained significant $(5.67$ vs. $6.48, F(1,56)=5.06, p<.05)$, whereas the dependability of the future spouse was marginally significant $(22.70$ vs. $24.94, F(1,56)=3.62, p<.07)$.

In addition to a main effect for marital status, the $2 \times 2$ (Gender $\times$ Marital Status) MANOVA on the optimism and trust measures also revealed a main effect for gender, $F(14,90)=$ $2.10, p<.05$, although the interaction between gender and marital status was not significant, $F(14,90)=1.24, n s$. Univariate tests indicated that women viewed other people as more benevolent, as measured by the BHB (85.91 vs. $80.11, F(1$, $103)=6.92, p<.01$ ), and trusted their fathers less than did male respondents $(32.87$ vs. $37.13, F(1,103)=4.03, p<.05)$, and that women indicated that their future spouse would be

\footnotetext{
${ }^{2}$ Respondents had also indicated whether they considered their dating relationship serious (yes or no). A $2 \times 2 \times 2$ (Gender $\times$ Parents' Marital Status $\times$ Seriousness of Dating Relationship) analysis of variance (ANOVA) revealed that those who considered their relationship serious $(n=62)$ reported greater trust of their partner than did those who did not consider their relationship serious (39.94 vs. $33.77, F(1$, $54)=7.81, p<.01)$. There were no significant interaction effects.
} 
more predictable than did men $(18.12$ vs. $16.42, F(1,103)=$ $6.07, p<.05)$.

To get a comparative measure of effect sizes for generalized versus specific trust beliefs, we calculated Cohen's (1969) " $d$ " statistic and averaged it across variables at the same level. Cohen's " $d$ " is a measure of effect size and represents the degree to which a standardized difference (calculated as the difference between two means divided by their average variance) departs from the null hypothesis. The effect size for the three generalized measures of trust was .03. At the interpersonal level, the average effect size was .08 for parental trust (average of .06 for trust of parents and .10 for trust between parents), .06 for trust of nonmarriage intimates ( 0.0 for the single measure of trust in best friend, and .08 for the two measures of trust in dating partner), and .12 for interpersonal trust in the context of marriage (using all four measures). The average "d" statistic for spouse dependability and marital optimism was .21 . It appears that differences in generalized trust for the PD and IF groups are demonstrably smaller than differences in interpersonal trust of specific others; and within the domain of interpersonal trust, the largest differences are found in trust beliefs related explicitly to marriage.

As found in Study 1, college-aged children of divorce were less optimistic about marriage than were college-aged children from intact families. To examine the predictors of marital optimism with the present sample of respondents, we conducted separate regression analyses for the PD and IF groups, using optimism about future marriage as the criterion variable. Given the considerably smaller sample size in this study, the predictor variables were limited to the three assumptions that both predicted marital optimism in Study 1 and were significant across groups (i.e., benevolence of the world, benevolence of people, and self-worth), and three measures of interpersonal trust: trust of best friend, trust of dating partner, and trust of spouse (i.e., dependability of spouse). (It should be noted that additional analyses were also run using all eight assumptions and using mother trust and father trust, and results were essentially unchanged.) As can be seen in Table 4, benevolence of people again accounted for the greatest proportion of variance in marital optimism for the PD group, $t(52)=2.11, p<.05$. The difference between the regression coefficients for benevolence of people for the PD and IF groups indicated a marginal twotailed trend, $t(108)=1.78, p<.08$. Trust in dating partner and benevolence of the world accounted for a significant proportion of the variance in marital optimism for the IF group, $t(56)=2.48, p<.01$ and $t(56)=2.30, p<.05$, respectively, and the regression coefficients for benevolence of the world differed across groups, $t(108)=2.36, p<.05$.

As in Study 1, the negative regression coefficient $(-.242)$ and positive zero-order correlation (.18) for benevolence of the world and marital optimism again suggest that benevolence of the world operated as a suppressor in the multiple regression analysis, rather than as a correlate of marital optimism in and of itself. As can be seen in Table 4, when these same regression analyses were repeated for Optimism about Future Relationships, present trust in dating partner accounted for the greatest proportion of variance in optimism about future dating relationships for the PD group, $t(52)=2.06, p<.05$, and self-worth emerged as the best predictor for the IF group, $t(56)=3.36, p<$
.005 . Only the regression coefficients for self-worth were significantly different across the PD and IF groups, $t(108)=2.15$, $p<.05$.

\section{Differences Within the PD Group}

A two-way (Gender $\times$ Age) MANOva on the optimism and trust scales (generalized and interpersonal) found no signifcant main effects or interactions due to gender or child's age at the time of divorce. Given past findings on the importance of age at time of divorce, univariate ANOVAS were conducted to determine whether there were specific variables of importance with respect to age. Only two significant effects were found across all the trust and optimism measures. Compared with respondents whose parents divorced when they were younger, those whose parents divorced when they were teenagers (between 11 and 19 years of age) reported a more negative view of both their mother and father before the divorce, $F(2,46)=3.36$, $p<.05$, and $F(2,46)=8.93, p<.001$, respectively. No differences were found on views of parents in the few years following the divorce or now.

Within the PD group, $47 \%(n=27)$ of the custodial parents had remarried. A $2 \times 2$ (Gender $\times$ Parental Remarriage) MANova found no significant main effects or interaction effects. Univariate analyses found a single significant effect, an interaction effect for gender and parental remarriage: Men whose custodial parent (usually the mother) had not remarried trusted their mother least, $F(1,46)=6.31, p<.05$.

\section{The Role of Conflict: Some Exploratory Analyses}

Recently, researchers (e.g., Enos and Handal, 1986; Emery, 1982) have suggested that a child's psychological adjustment and satisfaction are better explained by perceived conflict within the family than by the more objective measure of parents' marital status. With this in mind, we conducted some exploratory analyses to examine the possible long-term effects of parental conflict, rather than divorce per se, on college-aged children.

Respondents indicated the degree of conflict in their parents' relationship on a 5-point scale, with endpoints 0 and 4. Those in the IF group completed a single measure of conflict, whereas those in the PD group reported on parental conflict before the divorce, in the few years after the divorce, and now. IF respondents were considered to be from a "high conflict" family if they marked one of the two highest numbers ( 3 or 4$)$ and were considered "low conflict" if they marked one of the two lowest responses $(0$ or 1$)$. Those who indicated moderate conflict by checking the midpoint were not included in either group. Only six of the IF respondents indicated that there was high conflict in their parents' marriage. ${ }^{3}$

Almost all (44 of 57) respondents in the PD group reported a high level of conflict before the divorce; 13 reported present

\footnotetext{
${ }^{3}$ This group of six high-conflict IF respondents was significantly different from the low-conflict IF respondents in terms of trust in father, mother's trust in father, and father's trust in mother. Differences on other variables of interest were in the expected direction, although nonsignificant.
} 
Table 4

Regression Coefficients for the Prediction of Optimism About Future Relationships and Optimism About Marriage

\begin{tabular}{|c|c|c|c|c|c|}
\hline \multirow[b]{2}{*}{ Predictor variables } & \multicolumn{2}{|c|}{ PD group } & \multicolumn{2}{|c|}{ IF group } & \multirow[b]{2}{*}{$p^{\mathbf{2}}$} \\
\hline & $\beta$ & Unstand. & $\beta$ & Unstand. & \\
\hline \multicolumn{6}{|c|}{ Optimism about marriage } \\
\hline $\begin{array}{l}\text { Benevolence of people } \\
\text { Benevolence of the world } \\
\text { Self-worth } \\
\text { Trust in best friend } \\
\text { Trust in dating partner } \\
\text { Dependability of spouse }\end{array}$ & $\begin{array}{l}.460^{*} \\
-.242 \\
.091 \\
-.071 \\
.283 \\
.166 \\
\end{array}$ & $\begin{array}{r}.128 \\
-.061 \\
.025 \\
-.013 \\
.047 \\
.047\end{array}$ & $\begin{array}{l}-.055 \\
.292^{*} \\
.180 \\
-.016 \\
.335^{*} \\
.213\end{array}$ & $\begin{array}{r}-.025 \\
.117 \\
.051 \\
-.003 \\
.063 \\
.079 \\
\end{array}$ & $\begin{array}{c}<.08 \\
<.05 \\
n s \\
n s \\
n s \\
n s \\
\end{array}$ \\
\hline \multicolumn{6}{|c|}{ Optimisim about future relationships } \\
\hline $\begin{array}{l}\text { Benevolence of people } \\
\text { Benevolence of the world } \\
\text { Self-worth } \\
\text { Trust in best friend } \\
\text { Trust in dating partner } \\
\text { Dependability of spouse }\end{array}$ & $\begin{array}{l}-.093 \\
.185 \\
.038 \\
-.100 \\
.319^{*} \\
.270\end{array}$ & $\begin{array}{r}-.032 \\
.058 \\
.013 \\
-.022 \\
.065 \\
.094\end{array}$ & $\begin{array}{l}-.175 \\
.228 \\
.394^{*} \\
-.124 \\
.159 \\
.222\end{array}$ & $\begin{array}{r}-.101 \\
.117 \\
.143 \\
-.028 \\
.038 \\
.104\end{array}$ & $\begin{array}{c}n s \\
n s \\
<.05 \\
n s \\
n s \\
n s\end{array}$ \\
\hline
\end{tabular}

Note. PD group = parental divorce group; $n=57$. IF group $=$ intact family group; $n=57 . \beta=$ standardized regression coefficient; Unstand. $=$ unstandardized regression coefficient.

This $p$ value refers to the difference between the regression coefficients for the PD and IF groups.

$* p<.05$.

conflict between parents, and these 13 also indicated conflict both before and immediately after the divorce. This group of 13 constituted the high-conflict PD group. It is interesting to note that present conflict was uncorrelated with age at time of divorce, remarriage of custodial parent, or gender. In this highconflict group, there were seven men and six women, who were ages 4 through 17 at the time of divorce. Of the PD respondents who had not experienced continuous high conflict, 31 reported low conflict now and/or after the divorce; none were experiencing high conflict now, nor were they exposed to medium levels of conflict continuously since the divorce. These 31 constituted the low-conflict PD group. Only six respondents in this group reported low conflict prior to the divorce. Comparing the 13 high- (i.e., continuous) and 31 low-conflict (noncontinuous) PD respondents, a $2 \times 2$ (Gender $\times$ Conflict) MANOVA on the optimism measures and the generalized and interpersonal trust scales revealed a significant main effect for conflict, $F(20$, $24)=2.77, p<.01$. Univariate ANOvAs indicated that those exposed to continuous conflict trusted their mothers less (30.13 vs. $38.36, F(1,43)=6.58, p<.05)$, trusted their fathers less $(19.82$ vs. $34.61, F(1,43)=13.44, p<.001)$, and reported that their mothers trusted their fathers less $(17.51$ vs. $24.16, F(1$, $43)=8.64, p<.005$ ). Furthermore, continual high conflict appeared to affect generalized trust. Those who had experienced high levels of continuous conflict perceived other people as less benevolent (WAS: 14.56 vs. $18.52, F(1,43)=10.08, p<$ .005 ; BHB: 76.08 vs. $85.84, F(1,43)=5.66, p<.05)$ and the impersonal world as less benevolent (WAS: 12.14 vs. $17.77, F(1$, 43) $=14.27, p<.001$ ).

Two further analyses were conducted to explore the joint effects of parental divorce and conflict. The low-conflict PD respondents $(n=31)$ and the high-conflict PD respondents $(n=$
13) were each compared to the low conflict IF respondents ( $n=$ 37 ) in two separate $2 \times 2$ (Gender $\times$ Group) MANOVAs, using the optimism and trust scales as dependent measures. Both MANOVAS revealed significant main effects for group. Both the lowand high-conflict PD groups differed from the low-conflict IF group, $F(14,51)=8.82, p<.001$, and $F(20,27)=13.77, p<$ .001 , respectively. As shown in Table 5 , univariate tests found that the low-conflict PD group differed from the low-conflict IF group on measures of parental trust and dependability of spouse (the latter result was marginally significant). The lowconflict PD respondents trusted their mother less, $F(1,64)=$ $4.72, p<.05$, trusted their father less, $F(1,64)=8.83, p<.005$, believed their mother trusted their father less, $F(1,64)=66.19$, $p<.001$, believed their father trusted their mother less, $F(1$, $64)=49.56, p<.001$, and reported that they believed their spouse would be less dependable, $F(1,64)=2.87, p<.10$.

Univariate ANOVAS revealed differences between the highconflict PD respondents and the low-conflict IF respondents across all levels of trust. The high-conflict PD respondents reported a decreased belief in the benevolence of people on the WAS, $F(1,46)=9.12, p<.005$ and the Belief in Human Benevolence Scale, $F(1,46)=5.46, p<.05$, a decreased belief in the benevolence of the impersonal world on the WAS, $F(1,46)=$ $16.21, p<.001$, decreased trust in mother, $F(1,46)=29.82, p<$ .001 , decreased trust in father, $F(1,46)=89.05, p<.001$, decreased trust in father by mother, $F(1,46)=129.36, p<.001$, decreased trust in mother by father, $F(1,46)=76.05, p<.001$, and a decreased belief in the dependability of their future spouse, $F(1,46)=6.10, p<.05$. In addition, respondents whose parents had divorced and who indicated continuous conflict reported being less optimistic about the success of their future dating relationships, $F(1,46)=3.93, p<.05$ and less optimistic 
Table 5

Mean Values for High- and Low-Conflict PD Groups Compared With Low-Conflict IF group ${ }^{\mathrm{a}}$

\begin{tabular}{|c|c|c|c|}
\hline $\begin{array}{l}\text { Trust and optimism } \\
\text { variable }\end{array}$ & $\begin{array}{c}\text { Low- } \\
\text { conflict } \\
\text { PD group }\end{array}$ & $\begin{array}{c}\text { Low- } \\
\text { conflict } \\
\text { IF group }\end{array}$ & $\begin{array}{l}\text { High- } \\
\text { conflict } \\
\text { PD group }\end{array}$ \\
\hline \multicolumn{4}{|l|}{ Generalized trust } \\
\hline $\begin{array}{l}\text { Benevolence of people } \\
\text { (WAS) }\end{array}$ & 18.52 & 18.24 & $14.56^{* * *}$ \\
\hline $\begin{array}{l}\text { Benevolence of world } \\
\text { (WAS) }\end{array}$ & 17.77 & 17.24 & $15.27^{* * * * *}$ \\
\hline benevolence (BHB) & 85.84 & 84.27 & $76.08^{* *}$ \\
\hline \multicolumn{4}{|l|}{$\begin{array}{l}\text { Interpersonal trust } \\
\text { Parents }\end{array}$} \\
\hline Trust in mother & $38.36^{*}$ & 42.87 & $30.13^{* * * *}$ \\
\hline Trust in father & $34.61^{* * *}$ & 41.92 & $19.82^{* * * * *}$ \\
\hline $\begin{array}{l}\text { Mother's trust in } \\
\text { father }\end{array}$ & $24.16^{* * * *}$ & 40.54 & $17.51^{* * * * * *}$ \\
\hline $\begin{array}{l}\text { Father's trust in } \\
\text { mother }\end{array}$ & $28.84^{* * * * *}$ & 42.62 & $23.42^{* * * *}$ \\
\hline \multicolumn{4}{|l|}{ Intimates-nonmarriage } \\
\hline $\begin{array}{l}\text { Trust in best friend } \\
\text { Trust in dating partner }\end{array}$ & $\begin{array}{l}37.26 \\
40.10\end{array}$ & $\begin{array}{l}39.2 \\
39.11\end{array}$ & $\begin{array}{l}39.73 \\
36.92\end{array}$ \\
\hline $\begin{array}{l}\text { Optimism toward } \\
\text { dating relationships }\end{array}$ & 5.74 & 6.03 & $5.05^{* *}$ \\
\hline \multicolumn{4}{|l|}{ Intimates-marriage } \\
\hline Dependability of spouse & 23.81 & 25.03 & $21.64^{* *}$ \\
\hline Faith in spouse & 37.26 & 36.51 & 35.19 \\
\hline Predictability of spouse & 17.06 & 17.68 & 19.39 \\
\hline $\begin{array}{l}\text { Optimism toward } \\
\text { marriage }\end{array}$ & $5.74^{*}$ & 6.27 & $5.39 * *$ \\
\hline
\end{tabular}

Note. $n=31$ for low-conflict PD (parental divorce) group; $n=37$ for low-conflict IF (intact family) group; $n=13$ for high-conflict PD group. WAS = World Assumptions Scale; BHB = Belief in Human Benevolence Scale.

Asterisks indicate differences between presented mean and mean of low-conflict IF group (middle column).

${ }^{*} p<.10$. ** $p<.05$. *** $p<.005$. **** $p<.001$.

about their future marriage, $F(1,46)=6.36, p<.05$ than did those whose parents were still married and who indicated little parental conflict. ${ }^{4}$

\section{Discussion}

Study 2 attempted to further explore the findings of Study 1 by focusing on beliefs about marital optimism and the benevolence of other people held by college-aged students whose parents had been divorced and whose parents had not been divorced. The perceived benevolence of others was conceptually extended to include not only abstract, generalized beliefs about others, but also more specific beliefs about the extent to which particular others (parents, best friend, intimate dating partner, hypothetical spouse) are regarded as trustworthy. In this way, the level, or extent of generalizability of affected beliefs about benevolence could be ascertained. In addition, in this study optimism about one's future marriage was distinguished from more general optimism about one's own success in dating relationships. Thus, beliefs about the success of one's love relationships could be differentiated from narrower beliefs about marriage. The results of this study indicated that these concep- tual extensions and distinctions were important in providing some understanding of college-aged children's reactions to parental divorce many years after the event.

It appears that differences between college-aged children of divorce and college-aged children from intact families may be confined to the narrowest level of children's beliefs about benevolence, trust, and marital optimism. In this study, respondents whose parents had been divorced did not differ from those whose parents were still married on measures of generalized trust; in general, they did not perceive other people or the world as less benevolent. They did differ on several measures of interpersonal trust, but only those specifically related to marriage. Respondents from divorced families did not differ from their intact-family counterparts in terms of how much they trusted their present dating partner; they differed only in terms of how much they believed they would trust their spouse. Similarly, they did not differ in their beliefs about their success in future love relationships. It is only when these love relationships were specified as marriage that differences again appeared; those whose parents were divorced were less optimistic about the success of their own marriages.

Parental divorce seems to have a very specific impact on the long-term beliefs and assumptions of children whose parents have been divorced. Although the impact may be considerable and quite broad in the immediate aftermath of the divorce, over time the effect appears to become quite narrow and specifically tied to marital beliefs, the one realm where their experiences have differed from that of peers whose parents are still married.

It could be argued that in many ways the college-aged children of divorce have found an optimal way of coping with their experience. As is the case for other difficult life events, divorce requires children to assimilate their experience and reshape their theories of the world and themselves so that they can account for their experience (Epstein, 1980; Janoff-Bulman, 1985, 1989). By not overgeneralizing their experience, but rather, at least over time, narrowly confining its impact to beliefs about the most relevant life event-marriage-these individuals minimize the overall impact of the negative divorce experience.

Given their experience with their parents' marital breakup, it is not unreasonable for such individuals to regard their own marriages with greater caution and pessimism. For these respondents, divorce is more available as an event (Tversky \& Kahneman, 1974), and therefore more likely to be regarded as a common or frequent occurrence. Their decreased optimism about marriage and decreased belief in the dependability of a spouse may represent a realistic assessment of the dynamics of relationships. Respondents whose parents had been divorced reported lower levels of trust between their parents and also trusted both their mother and father less while growing up. They personally witnessed a breakdown of trust between two

\footnotetext{
4hen these same analyses were conducted using the entire IF group as a comparison, results remained essentially unchanged. Differences between the low-conflict PD and all IF respondents were confined to measures of parent trust and spouse dependability, whereas differences between high-conflict PD and all IF respondents appeared at all levels of trust and optimism.
} 
people, and are highly aware of the dyadic nature of a marital relationship. Their awareness of the interdependent nature of marital relationships was apparent in the regression analyses for marital optimism in both Study 1 and Study 2. The best predictor of marital optimism for college-aged children of divorce, but not their intact-family counterparts, was their assumption about the benevolence of people. The more they viewed people as good, caring, helpful and kind, the more likely they were to believe that their marriage would be a success. Respondents whose parents had divorced appeared all too aware-at the level of emotional experience-that some marriages do end; being a fine, worthy person oneself is not a guarantee of marital success, and marriage is not a guarantee of trust between partners, but an interdependent venture that might fail.

The exploratory analyses of parental conflict suggest the importance in future studies of differentiating between the event of parental divorce and the experience of high conflict between one's parents. Conflict seems to be associated with far greater consequences. A divorce that eventually eases the friction between parents continues to be associated with decreased trust in parents and somewhat greater pessimism about marriage; yet relatively positive assumptions about other people and the world in general are, if affected initially, over time restored. This appears to be the case even for those exposed to high conflict prior to parental divorce, which characterized the overwhelming majority of those in the low-conflict group in Study 2. Repeated exposure to a parental relationship that is difficult and strained represents a continuous process, and in this study was associated not only with decreased trust in parents and decreased optimism about both dating and marital relationships, but also with more negative assumptions about the benevolence of others and the world. Generalized trust seemed to have been affected. A divorce that eventually reduces the tension between parents is conceivably incorporated into the child's world view as a failed marriage. A parental relationship that involves unresolved conflict over time provides the child with a more disturbing view of the world. The child appears to generalize the negative aspects of the parents' relationship to the world and people in general.

In the two studies reported, respondents were college students, and thus the samples represented a relatively healthy population. It might be argued that those who have been most affected by their parents' divorce may not make it to college, and thus the generalizability of these results remains an issue. Nevertheless, in these studies an attempt was made to make comparisons with respondents of similar background and circumstances except for parental divorce, a necessary corrective to clinical accounts of children of divorce. A recent, popular book by Wallerstein and Blakeslee (1989), for example, reports the findings of Wallerstein's impressive longitudinal work with children of divorce and provides a relatively negative picture of these now late adolescents. Such a study provides us with a wealth of important, in-depth information about the experiences of these children, but leaves open the question of comparisons. Many adolescents in her sample reported fears of intimacy and anxiety over betrayal or never finding love. Yet it is certainly possible that these are central, anxiety-producing issues for most adolescents, regardless of parental marital status, because dating and intimacy represent foremost developmental tasks for this age group.

Much future research is needed. Do married children of divorce in fact trust their spouses less and remain less optimistic about their relationships, or do they simply differ in their projected beliefs about marriage? A question we are presently addressing is whether children of divorce view all marriages, or simply their own marriages, more pessimistically (i.e, universal vs. unique vulnerability; Perloff, 1983). Furthermore, it is interesting to consider the impact of positive, serious relationships on beliefs about marriage. Involvement in a dating relationship was only cursorily examined in the present research, and the effect of relationship qualities (e.g., length, satisfaction, seriousness) on marital optimism remains an open question. In the cognitive domains examined in the present research, it appears that college-aged children of divorce may fare quite well over time. The larger picture of their adjustment and well-being, involving a complex array of psychological dimensions, awaits further research. Prospective, longitudinal studies would enable researchers not only to address the problems inherent in retrospective studies, but to determine the contribution of variables such as the quality of parent-child relationships, the psychological well-being of custodial parents, and parental conflict on children's postdivorce adjustment over time.

\section{References}

Bane, M. J. (1979). Marital disruption and the lives of children. In G. Levinger \& O. C. Moles (Eds.), Divorce and separation. New York: Basic Books.

Booth, A., Brinkerhoff, D. B., \& White, L. K. (1984). The impact of parent divorce on courtship. Journal of Marriage and the Family. 46, 85-94.

Cohen, J. (1969). Statistical power analysis for the behavioral sciences. San Diego, CA: Academic Press.

Cohen, J., \& Cohen, P. (1975). Applied multivariate regression/correlational analyses for the behavioral sciences. Hillsdale, NJ: Erlbaum.

Emery, R. E. (1982). Interparental conflict and the children of discord and divorce. Psychological Bulletin, 92, 310-330.

Enos, D. M., \& Handal, P. J. (1986). The relation of parent marital status and perceived family conflict to adjustment in White adolescents. Journal of Consulting and Clinical Psychology, 54, 820-824.

Epstein, S. (1973). The self concept revisited, or a theory of a theory. American Psychologist, 28, 404-416.

Epstein, S. (1980). The self-concept: A review and the proposal of an integrated theory of personality. In E. Staub (Ed.), Personality: Basic aspects and current research. Englewood Cliffs, NJ: Prentice-Hall.

Erikson, E. (1968). Identity: Youth and crisis. New York: Norton.

Felner, R. D., Stolberg, A., \& Cowen, E. L. (1975). Crisis events and school mental health referral patterns of young children. Journal of Consulting and Clinical Psychology, 43, 305-310.

Glenn, N. D. (1985, June). Children of divorce. Psychology Today, pp. 68-69.

Glick, P. C. (1979). Children of divorced parents in a demographic perspective. Journal of Social Issues, 35, 170-182.

Glick, P. C. (1984). How American families are changing. American Demographics, 6, 20-27.

Greenberg, E. F., \& Nay, W. R. (1982). The intergenerational transmission of marital instability reconsidered. Journal of Marriage and the Family, 44, 335-347.

Hess, R. D. \& Camara, K. A. (1979). Post-divorce family relationships 
as mediating factors in the consequences of divorce for children. Journal of Social Issues, 35, 79-96.

Hetherington, E. M, Cox, M, \& Cox, R. (1979). Play and social interaction in children following divorce. Journal of Social Issues, 35, 26-49.

Horowitz, M. J. (1980). Psychological response to serious life events. In V. Hamilton \& D. Warburton (Eds.), Human stress and cognition. New York: Wiley.

Horowitz, M. J. (1982). Stress response syndromes and their treatment. In L. Goldberger \& S. Breznitz (Eds.), Handbook of stress. New York: Free Press.

Janoff-Bulman, R. (1979). Characterological versus behavioral selfblame: Inquiries into depression and rape. Journal of Personality and Social Psychology, 37, 1798-1809.

Janoff-Bulman, R. (1985). The aftermath of victimization: Rebuilding shattered assumptions. In C. Figley (Ed.), Trauma and its wake (Vol. 1). New York: Brunner/Mazel.

Janoff-Bulman, R. (1989). Assumptive worlds and the stress of traumatic events: Applications of the schema construct. Social Cognition, 7, 113-136.

Janoff-Bulman, R., \& Frieze, I. H. (1983). A theoretical perspective for understanding reactions to victimization. Journal of Social Issues, $39,1-17$.

Kalter, N. (1977). Children of divorce in an outpatient psychiatric population. American Journal of Orthopsychiatry, 51, 85-100.

Kulka, R. A., \& Weingarten, H. (1979). The long-term effects of parental divorce in childhood on adult adjustment. Journal of Social Issues, 35, 26-49.

Larzelere, R. E., \& Huston, T. L. (1980). The Dyadic Trust Scale: Toward understanding interpersonal trust in close relationships. Journal of Marriage and the Family, 42, 595-604.

Longfellow, C. (1979). Divorce in context: Its impact on children. In G. Levinger \& O. C. Moles (Eds.), Divorce and separation. New York: Basic Books.

McDermott, J. F., Jr. (1970). Divorce and its psychiatric sequelae in children. Archives of General Psychiatry, 23, 421-427.

Norton, A. J., \& Glick, P. C. (1979). Marital instability in America: Past, present and future. In G. Levinger \& O. C. Moles (Eds.), Divorce and separation. New York: Basic Books.

Parish, T. S., \& Taylor, L. (1979). The impact of divorce and subsequent father absence on children's and adolescents' self-concepts. Journal of Youth and Adolescence, 8, 427-432.

Parkes, C. M. (1971). Psych-social transitions: A field study. Social Science and Medicine, 5, 101-115.

Parkes, C. M. (1975). What becomes of redundant world models? A contribution to the study of adaptation to change. British Journal of Medical Psychology, 48, 131-137.
Perloff, L. (1983). Perceptions of vulnerability to victimization. Journal of Social Issues, 39, 41-61.

Peterson, J. L., \& Zill, N. (1983). Marital disruption, parent/child relationships, and behavioral problems in children. Paper presented at the annual meetings of the Society for Research in Child Development, Washington, DC.

Rempel, J. K., Holmes, J. G., \& Zanna, M. P. (1985). Trust in close relationships. Journal of Personality and Social Psychology, 49, $95-$ 112.

Santrock, J. W, \& Warshak, R. A. (1979). Father custody and social development in boys and girls. Journal of Social Issues, 35, 122-135.

Slater, E. J, Stewart, K. J., \& Linn, M. W. (1983). The effects of family disruption on adolescent males and females. Adolescence, 18, 931942.

Taylor, S. E., \& Brown, J. D. (1988). Illusion and well-being: A social psychological perspective on mental health. Psychological Bulletin, 103, 193-210.

Thornton, D., \& Kline, P. (1982). Reliability and validity of the Belief in Human Benevolence Scale. British Journal of Social Psychology, 2I, $57-62$.

Tversky, A., \& Kahneman, D. (1974). Judgment under uncertainty: Heuristics and biases. Science, 185, 1124-1131.

Wallerstein, J. S. (1983). Children of divorce: Stress and developmental tasks. In N. Garmezy \& M. Rutter (Eds.), Stress, coping, and development in children. New York: McGraw-Hill.

Wallerstein, J. S. (1987). Children of Divorce: Report of a ten year follow-up of early latency-age children. American Journal of Orthopsychiatry, 2, 199-211.

Wallerstein, J. S, \& Blakeslee, S. (1989). Second chances: Men, women, and children a decade after divorce. New York: Ticknor \& Fields.

Wallerstein, J. S, \& Kelly, J. (1975). The effects of parental divorce: The experiences of the preschool child. Journal of the American Academy of Child Psychiatry, 14, 600-616.

Wallerstein, J. S., \& Kelly, J. (1980). Surviving the breakup: How children and parents cope with divorce. New York: Basic Books.

Weiss, R. S. (1979). Growing up a little faster: The experience of growing up in a single-parent household. Journal of Social Issues, 35, 97-111.

Young, E. R, \& Parish, T. S. (1977). Impact of father absence during childhood on the psychological adjustment of college females. Sex Roles, 3, 217-227.

Zung, W. K. (1965). A self-rating depression scale. Archives of General Psychiatry, 12, 63-70.

Received October 26, 1989

Revision received May 17, 1990 Accepted June 4, 1990 